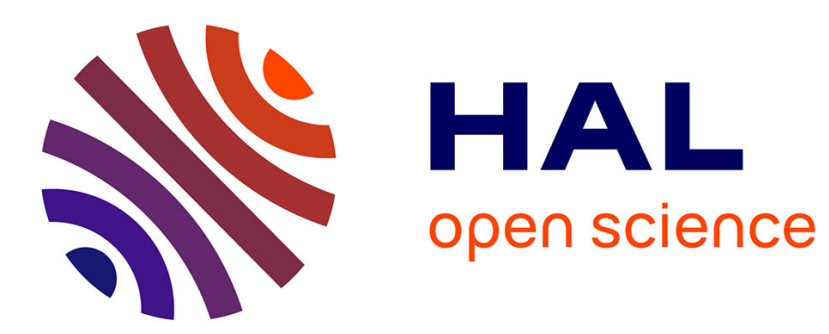

\title{
Stator Current Analysis by Subspace Methods for Fault Detection in Induction Machines
}

Youness Trachi, El Houssin El Bouchikhi, Vincent V. Choqueuse, Mohamed Benbouzid

\section{- To cite this version:}

Youness Trachi, El Houssin El Bouchikhi, Vincent V. Choqueuse, Mohamed Benbouzid. Stator Current Analysis by Subspace Methods for Fault Detection in Induction Machines. Industrial Electronics Society, IECON 2015 - 41st Annual Conference of the IEEE, Nov 2015, Yokohama, Japan. 10.1109/IECON.2015.7392639 . hal-01264782

\section{HAL Id: hal-01264782 \\ https://hal.science/hal-01264782}

Submitted on 1 Feb 2016

HAL is a multi-disciplinary open access archive for the deposit and dissemination of scientific research documents, whether they are published or not. The documents may come from teaching and research institutions in France or abroad, or from public or private research centers.
L'archive ouverte pluridisciplinaire HAL, est destinée au dépôt et à la diffusion de documents scientifiques de niveau recherche, publiés ou non, émanant des établissements d'enseignement et de recherche français ou étrangers, des laboratoires publics ou privés. 


\title{
Stator Current Analysis by Subspace Methods for Fault Detection in Induction Machines
}

\author{
Youness Trachi ${ }^{1}$, Elhoussin Elbouchikhi ${ }^{2}$, Vincent Choqueuse ${ }^{1}$, and Mohamed Benbouzid ${ }^{1}$ \\ ${ }^{1}$ University of Brest, EA 4325 LBMS, Brest, France \\ ${ }^{2}$ ISEN Brest, EA 4325 LBMS, Brest, France \\ Email: Youness.Trachi@univ-brest.fr, elbouchikhi@isen-bretagne.fr, \\ Vincent.Choqueuse@univ-brest.fr, and Mohamed.Benbouzid@univ-brest.fr
}

\begin{abstract}
This paper aims to develop a condition monitoring architecture for induction machines, with focus on bearing faults. The main objective of this paper is to identify fault signatures at an early stage by using high-resolution frequency estimation techniques. In particular, we present two subspace methods, which are Root-MUSIC and ESPRIT. Once the frequencies are determined, the amplitude estimation is obtained by using the Least Squares Estimator (LSE). Finally, the amplitude estimation is used to derive a fault severity criterion. The experimental results show that the proposed architecture has the ability to measure the faults severity.
\end{abstract}

Keywords-Induction machine, bearing fault detection, stator current analysis, subspace techniques, Root-MUSIC, ESPRIT, fault severity.

\section{INTRODUCTION}

Recently, the induction machines have become the most popular machines used in industrial applications thanks to their advantages such as low cost, reliability, availability, and high robustness. Unfortunately, these machines can be subjected to various faults. These faults can be categorized into two main classes: electrical and mechanical faults [1]-[3]. The electrical faults include stator winding short circuit, broken rotor bar, and broken end-ring. Besides, the mechanical faults comprise rotor eccentricity, bearing faults, shaft misalignment, and load faults. in order to reduce operating and maintenance costs, it is desirable to develop and search for reliable techniques allowing fault detection at an early stage [4]. Many condition monitoring techniques for induction machines can be exploited to detect the presence of faults such as vibration monitoring, temperature monitoring, oil monitoring, etc. However, these techniques are expensive and require additional sensors to be fitted to the machines. A solution to this problem is to use the stator current analysis. In fact, these techniques allow to use additional sensors in induction machine drives. Moreover, the stator currents are usually available for other purposes such as protection and control. In addition of that, the use of stator current presents other advantages such as its accessibility, the ease of implementation, the information richness, and the ability to detect electrical and mechanical faults [5].

Induction machines failures have an impact over intrinsic parameters such as magnetomotive forces, self and mutual inductances and stator currents. Consequently, the motor currents signature analysis (MCSA) have been widely investigated by researchers and engineers [6]. Several induction machines studies using the stator current prove that faults in induction machines introduce additional frequency components in the stator current spectrum [5]. Furthermore, the majority of mechanical or electrical faults are manifested by amplitude and/or frequency modulation of the stator current signal [7], [8]. The challenge of condition monitoring in induction machine using stator currents is to extract fault frequencies. Among the proposed techniques in the literature for stator current analysis, we can find techniques based on the Fourier Transform (FT), Fast Fourier Transform (FFT) and periodogram for stationary environments and time-frequency, time-scale, and demodulation techniques for non-stationary environments [8], [9]. A general review of induction machines monitoring and faults diagnosis techniques can be found in [5], [10]. If an a priori signal model is assumed, parametric methods can be employed to improve the frequency resolution. These techniques are generally called high-resolution methods and include two sub-classes: linear prediction methods and subspace techniques. The linear prediction class contains algorithms such as autoregressive-moving-average (ARMA) methods. The subspace methods include MUSIC and ESPRIT approaches [3], [11]-[13].

In the present paper, we consider the bearing faults detection based on stator currents analysis. The bearing faults are due to several reasons such as vibrations, internal stress, power electronic devices, and inherent eccentricity. The bearing faults has received a great deal of attention [7], [9]. Two main contributions can be listed herein. The first one considers the introduction of additional frequency components due to the presence of the fault [9], [14]. The second contribution demonstrates that bearing faults introduce both eccentricity and load oscillations which leads to amplitude and frequency modulation of the stator currents [2], [7]. This paper proposes to use subspace techniques in order to overcome the poor resolution of the FFT-based approaches [1], [3]. They are concerned with estimating unknown signal parameters from stator current measurements. These approaches require a priori knowledge about the signal to be processed. In fact, a stator model is used in order to develop a frequency estimators. Moreover, the proposed methods require to estimate the number of frequency components known in signal processing community as model order selection. This model order is determined using information criteria rules [15]. Furthermore, we present frequencies amplitude estimation by using the Least Squares Estimator (LSE). Finally a fault severity is proposed in order 
to measure the fault degree using the algorithm introduced in [16].

\section{PROBLEM Formulation}

In this section, we present bearing faults effects over the stator current. Moreover, the stator current model is proposed in order to develop a fault detection technique.

\section{A. Bearing Faults}

We consider the problem of rolling-element bearings. These faults are the most frequent faults in induction machines [7]. The bearing consists mainly of outer raceway, inner raceway, balls, and the cage which assures equidistance between the balls. The bearing faults can be classified according to the affected element

$$
\begin{array}{ll}
- & \text { Outer raceway defect, } \\
- & \text { Inner raceway defect, } \\
- & \text { Balls defect, } \\
- & \text { Cage defect. }
\end{array}
$$

For each type of bearing faults, a characteristic frequency $f_{c}$ can be associated [7]. Their expressions for the four considered fault types are given by

$$
\begin{aligned}
& f_{o}=\frac{N_{b}}{2} f_{r}\left(1-\frac{D_{b}}{D_{c}} \cos \beta\right) \\
& f_{i}=\frac{N_{b}}{2} f_{r}\left(1+\frac{D_{b}}{D_{c}} \cos \beta\right) \\
& f_{b}=\frac{D_{c}}{D_{b}} f_{r}\left(1-\frac{D_{b}^{2}}{D_{c}^{2}} \cos ^{2} \beta\right), \\
& f_{c a}=\frac{1}{2} f_{r}\left(1-\frac{D_{b}}{D_{c}} \cos \beta\right)
\end{aligned}
$$

where $f_{o}$ is the outer raceway fault frequency, $f_{i}$ the inner raceway fault frequency, $f_{b}$ the ball fault frequency, $f_{c a}$ the cage fault frequency, $N_{b}$ the number of balls, $f_{r}$ the mechanical rotor speed in Hertz, $D_{b}$ the ball diameter, $D_{c}$ the bearing pitch diameter, and $\beta$ the contact angle of the balls on the races.

The characteristic bearing fault frequencies can be reflected on stator currents. The relationship between these frequencies and current frequency can be described by

$$
f_{b f}=\left|f_{s} \pm k f_{c}\right|
$$

where $f_{s}$ is the supply fundamental frequency, $f_{c}$ is the bearing fault characteristic frequency, and $k \in \mathbb{N}^{*}$.

\section{B. Stator Current Model}

Induction machine stator current in presence of bearing faults can be expressed by a model, characterized by fundamental component, harmonics and faults. In this type of modeling, the observed model can be seen as a sum of a deterministic signal and noise. In this case, the stator current can be described by the following model

$$
x[n]=\sum_{k=0}^{L-1} a_{k} e^{j\left(2 \pi f_{k} \times \frac{n}{F_{s}}+\phi_{k}\right)}+b[n],
$$

where

- $\quad x[n]$ denotes the stator current samples,
- $\quad b[n] \sim \mathcal{N}_{c}\left(0, \sigma^{2}\right)$ is a complex circular white Gaussian noise i.e.:

$$
\begin{aligned}
& E[b(n)]=E[b(n) b(n+\tau)]=0, \\
& E\left[b(n) b^{*}(n+\tau)\right]=\sigma^{2} \delta(\tau),
\end{aligned}
$$

where $E[],.(.)^{*}$, and $\delta($.$) correspond to the statistical$ expectation, the complex conjugate, and the Dirac delta, respectively,

- $\quad L$ represents the model order,

- $F_{s}$ is the sampling frequency,

- $a_{k}, f_{k}$, and $\phi_{k}$ are the signal parameters (amplitude, frequency, and initial phase, respectively) of the $k^{t h}$ component.

At time $n=0,1,2,3, \ldots$ the observed stator current vector $\mathbf{x}(n)$, defined as $\mathbf{x}(n)=\left[\begin{array}{lll}x(n) & \ldots & x(n+M-1)\end{array}\right]^{T}$, can be expressed as

$$
\mathbf{x}(n)=\mathbf{A}\left(f_{k}\right) \mathbf{v}+\mathbf{b}(n),
$$

where

- $\quad M$ is the length of the time window vector,

- $(.)^{T}$ refers to transpose,

$-\quad \mathbf{x}[n]=\left[\begin{array}{lll}x[n] & \ldots & x[n+M-1\end{array}\right]^{T}$ is a $M \times 1$ column vector containing the stator current samples,

- $\mathbf{b}(n)=\left[\begin{array}{lll}b[n] & \ldots & b[n+M-1\end{array}\right]^{T}$ is a $M \times 1$ column vector containing the noise samples,

- $\quad \mathbf{v}$ is a $L \times 1$ column vector containing the amplitudes and phases of the frequencies. This vector is given by

$$
\mathbf{v}=\left[\begin{array}{llll}
a_{0} e^{j \phi_{0}} & a_{1} e^{j \phi_{1}} & \ldots & a_{L-1} e^{j \phi_{L-1}}
\end{array}\right],
$$

- $\mathbf{A}\left(f_{k}\right)$ is a $M \times L$ Vandermonde matrix given by

$$
\mathbf{A}\left(f_{k}\right)=\left[\begin{array}{cccc}
1 & 1 & \ldots & 1 \\
e^{j 2 \pi f_{0} \times \frac{1}{F_{s}}} & e^{j 2 \pi f_{1} \times \frac{1}{F_{s}}} & \ldots & e^{j 2 \pi f_{L-1} \times \frac{1}{F_{s}}} \\
\vdots & \vdots & \vdots & \vdots \\
e^{j 2 \pi f_{0} \times \frac{M-1}{F_{s}}} & e^{j 2 \pi f_{1} \times \frac{M-1}{F_{s}}} & \ldots & e^{j 2 \pi f_{L-1} \times \frac{M-1}{F_{s}}}
\end{array}\right]
$$

The main objective of the remaining sections is to propose parameters estimation techniques which will allow to extract the fault characteristic frequencies and to measure the fault severity based on the stator current observations. The proposed architecture is described by Fig. 1 .

\section{Subspace TeChNiQues}

Many signal processing applications use methods called high-resolution techniques for frequency estimation, such applications include electrical signal processing [11]-[13]. These techniques are mainly based on the eigendecomposition of the covariance matrix and knowledge of the model order. These methods are presented in the following subsections.

\section{A. Covariance Matrix}

Subspace techniques are based on the covariance eigenvalue decomposition. In fact, the covariance matrix is decomposed in two orthogonal subspaces: signal subspace and noise 


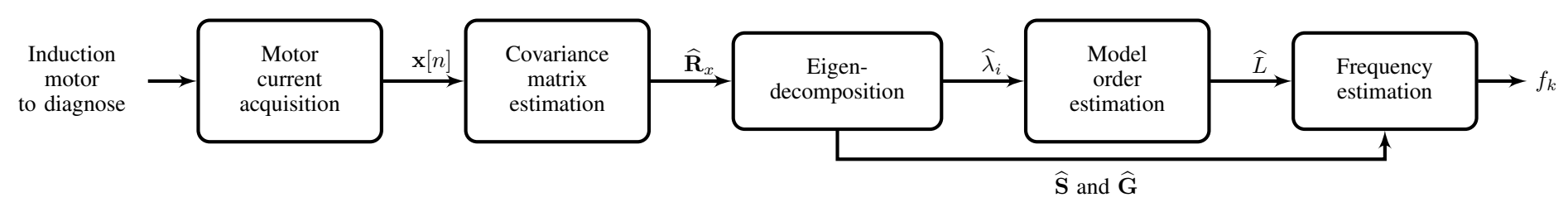

Fig. 1. Frequency estimation by using subspace techniques.

subspace. It can be written in the form of two covariances

$$
\mathbf{R}_{x}=E\left[\mathbf{x}[n] \mathbf{x}^{H}[n]\right]=\mathbf{R}_{s}+\mathbf{R}_{n},
$$

where $\mathbf{R}_{s}$ denotes the signal covariance matrix, $\mathbf{R}_{n}$ is the noise covariance matrix, and $(.)^{H}$ refers to Hermitian matrix transpose.

The covariance matrix eigenvalues decomposition can be written as follows

$$
\mathbf{R}_{x}=\mathbf{U} \boldsymbol{\Lambda} \mathbf{U}^{H}=\left[\begin{array}{ll}
\mathbf{S} & \mathbf{G}
\end{array}\right]\left[\begin{array}{cc}
\boldsymbol{\Lambda}_{s} & 0 \\
0 & \boldsymbol{\Lambda}_{n}
\end{array}\right]\left[\begin{array}{ll}
\mathbf{S} & \mathbf{G}
\end{array}\right]^{H},
$$

where $\boldsymbol{\Lambda}_{s}$ and $\boldsymbol{\Lambda}_{n}$ are the diagonal matrix containing eigenvalues of signal and noise subspaces arranged in descending order, respectively ( $\mathbf{S}$ and $\mathbf{G}$ are the associated orthonormal eigenvectors, respectively).

The orthogonality between signal and noise subspaces $\left(\mathbf{S}^{H} \mathbf{S}=\mathbf{I}\right.$ and $\left.\mathbf{G}^{H} \mathbf{G}=\mathbf{I}\right)$, can be explained by the following expressions

$$
\begin{aligned}
& \mathbf{P}_{G} \mathbf{S}=0, \\
& \mathbf{P}_{S} \mathbf{G}=0,
\end{aligned}
$$

where $\mathbf{P}_{S}=\mathbf{S} \mathbf{S}^{H}$ and $\mathbf{P}_{G}=\mathbf{G G}^{H}$ are the projection operators onto signal and noise subspaces, respectively.

In practice, the theoretical covariance matrix $\mathbf{R}_{x}$ and its eigendecomposition are not known but can be estimated from observations as follows

$$
\widehat{\mathbf{R}}_{x}(n)=\frac{1}{G} \sum_{n=1}^{G} \mathbf{x}(n) \mathbf{x}^{H}(n),
$$

where $\mathbf{x}(n)=\left[\begin{array}{lll}x(n) & \ldots & x(n+M-1)\end{array}\right]^{T}$ has length $M$. Since we have $N$ observations of $x[n], G=N-M+1$.

The purpose of eigendecomposition analysis is to define the signal and the noise subspaces. In practice, we estimate them by using eigenvectors and eigenvalues of the sample correlation matrix. In fact, the greatest eigenvalues $L$ of the covariance matrix in (11) are associated with the signal subspace. The corresponding eigenvectors span the signal subspace whereas, the remaining eigenvectors span the noise subspace. It appears then that the knowledge of the model order is indispensable. That's why, the following subsection deal with model order estimation.

\section{B. Model Order Estimation}

The knowledge of the sinusoids number in the stator current samples is mandatory in order to perform stator current spectral analysis. The model order estimation is obtained by minimizing the Akaike Information Criterion (AIC) or the
Minimum Description Length (MDL) described in [15]. In this approach, the model order is determined by the eigenvalue decomposition of the covariance matrix. Criteria are given by the following expressions

$$
A I C(k)=-2 \log \left(\frac{\prod_{i=k+1}^{p} \widehat{\lambda}_{i}^{\frac{1}{p-k}}}{\frac{1}{p-k} \sum_{i=k+1}^{p} \widehat{\lambda}_{i}}\right)^{(p-k) N}+2 k(2 p-k),
$$

$$
M D L(k)=-\log \left(\frac{\prod_{i=k+1}^{p} \widehat{\lambda}_{i}^{\frac{1}{p-k}}}{\frac{1}{p-k} \sum_{i=k+1}^{p} \widehat{\lambda}_{i}}\right)^{(p-k) N}+\frac{1}{2} k(2 p-k) \log (N)
$$

where $\widehat{\lambda}_{i}$ and $\mathrm{p}$ denote the ordered eigenvalues and the eigenvectors number of the covariance matrix $\widehat{\mathbf{R}}_{x}$, respectively.

The model order of signal is determined as the value of $k \in$ $\{0,1, \ldots ., p-1\}$, that minimizes the AIC or MDL criterion.

\section{Root-MUSIC}

MUSIC (MUltiple SIgnal Classification or MUltiple SIgnal Characterization) method is a technique in statistical estimation theory based on the use of subspace concept. This frequency estimation technique exploits the orthogonality between signal and noise subspaces [6], [17], [18]. After these subspaces are identified, a frequency estimation function is used to find the component frequencies by using eigenvectors of the noise subspace. This frequency estimation is obtained by finding the highest local maxima $L$ of the following cost function

$$
\widehat{f}_{k}=\underset{\{f\}}{\operatorname{argmax}} \frac{1}{\left\|\mathbf{a}^{H}(f) \widehat{\mathbf{G}}\right\|_{F}^{2}}
$$

where $\widehat{\mathbf{G}}$ is formed of the orthonormal eigenvectors spanning the noise subspace, $\|\cdot\|_{F}$ denotes the Frobenius norm, and $\mathbf{a}^{H}(f)$ denotes the row vector given by

$$
\mathbf{a}^{H}(f)=\left[1, e^{\frac{j 2 \pi f}{F_{s}}}, e^{\frac{j 2 \pi 2 f}{F_{S}}}, \ldots \ldots \ldots, e^{\frac{j 2 \pi(M-1) f}{F_{S}}}\right] .
$$

To avoid searching for the peaks of the cost function given by (13), Root-MUSIC seems to be a solution. In fact, RootMUSIC method is a polynomial-rooting technique, that converts the pseudo-spectrum function in (13) into a polynomial function given by 15 . The $L$ roots of $\mathbf{Q}(z)$ have amplitude $<1$ and are close to the unit circle [18]. In this case, we can 
use a polynomial representation as follows

$$
\mathbf{Q}(z)=\mathbf{a}^{T}\left(\frac{1}{z}\right) \widehat{\mathbf{G}} \widehat{\mathbf{G}}^{H} \mathbf{a}(z),
$$

where $z=e^{\frac{j 2 \pi f}{F_{s}}}$ and $\mathbf{a}^{T}(z)=\left[1, z^{-1}, z^{-2}, \ldots \ldots \ldots, z^{M-1}\right]$.

Finally, finding $\widehat{z}_{k}$ roots of $\mathbf{Q}(z)$ is equivalent to find frequencies according to the following equation

$$
\widehat{f}_{k}=\frac{\arg \left(\widehat{z}_{k}\right)}{2 \pi} \times F_{s} .
$$

\section{ESPRIT}

ESPRIT (Estimation of Signal Parameters via Rotational Invariance Techniques) is a parametric method of signal processing based on the notion of subspaces [19]. Indeed the separation between two subspaces in the ESPRIT technique is based on singular value decomposition of the covariance matrix $\mathbf{R}_{x}$. It exploits the invariance property by rotation of the signal subspace to estimate frequencies of the sinusoidal model [18]. Furthermore, ESPRIT has significant performance compared to MUSIC in terms of cost calculation and data storage [19]. Another advantage of ESPRIT, is the fact that, it does not need to find peaks of pseudo-spectrum function. In fact, due to the characteristics mentioned, ESPRIT is the first method recommended in applications of frequency estimation [18].

The objective of ESPRIT method is to solve the following rotation equation

$$
\mathbf{S}=\mathbf{A}\left(f_{k}\right) \mathbf{T}
$$

Let $\mathbf{A}_{1}=\left[\begin{array}{ll}\mathbf{I}_{M-1} & 0\end{array}\right] \mathbf{A}$ and $\mathbf{A}_{2}=\left[\begin{array}{ll}0 & \mathbf{I}_{M-1}\end{array}\right] \mathbf{A}$ be unstaggered and staggered components of the matrix $\mathbf{A}$, respectively.

So, we can demonstrate the following equality

$$
\mathbf{A}_{2}=\mathbf{A}_{1} \Omega
$$

where $\boldsymbol{\Omega}=\operatorname{diag}\left(e^{j 2 \pi f_{0}}, e^{j 2 \pi f_{1}}, \ldots, e^{j 2 \pi f_{L-1}}\right)$ contains the unknown parameters.

Let $\mathbf{S}_{1}=\left[\begin{array}{ll}\mathbf{I}_{M-1} & 0\end{array}\right] \mathbf{S}$ and $\mathbf{S}_{2}=\left[\begin{array}{ll}0 & \mathbf{I}_{M-1}\end{array}\right] \mathbf{S}$ be unstaggered and staggered signal subspaces, respectively.

According to the previous equations, we can write

$$
\left\{\begin{array}{l}
\mathbf{S}_{1}=\mathbf{A}_{1} \mathbf{T} \\
\mathbf{S}_{2}=\mathbf{A}_{2} \mathbf{T}
\end{array}\right.
$$

From equations (18) and (19), we obtain

$$
\mathbf{S}_{2}=\mathbf{S}_{1} \mathbf{T}^{-1} \boldsymbol{\Omega} \mathbf{T}=\mathbf{S}_{1} \mathbf{\Phi},
$$

where $\mathbf{\Phi}=\mathbf{T}^{-1} \boldsymbol{\Omega} \mathbf{T}$ is the relation between the two subspaces rotations. Indeed, eigenvalues of $\boldsymbol{\Phi}$ must be equal to diagonal elements of $\Omega$ and columns of $\mathbf{T}$ are eigenvectors of $\boldsymbol{\Phi}$.

Using the Least-squares method [20], $\boldsymbol{\Phi}$ is given by

$$
\mathbf{\Phi}=\left(\mathbf{S}_{1}^{H} \mathbf{S}_{1}\right)^{-1} \mathbf{S}_{1}^{H} \mathbf{S}_{2} .
$$

In practice, we can estimate frequencies of signal according to the following expression

$$
\widehat{f}_{k}=\frac{\arg \left(v_{k}\right)}{2 \pi} \times F_{s},
$$

where $v_{k}$ are eigenvalues of $\boldsymbol{\Phi}$ estimate given by

$$
\widehat{\boldsymbol{\Phi}}=\left(\widehat{\mathbf{S}}_{1}^{H} \widehat{\mathbf{S}}_{1}\right)^{-1} \widehat{\mathbf{S}}_{1}^{H} \widehat{\mathbf{S}}_{2}
$$

\section{Proposed FAUlt Detection ApPROACH}

This section presents the proposed fault detection approach. First, an amplitude estimator is proposed based on LSE. Then, a fault detection criterion is described. Finally, the proposed algorithm for bearing fault detection is described.

\section{A. Amplitude Estimation}

The amplitude estimation for each frequency component is realized by the Least Squares Estimator (LSE). In practice, the LSE is widely used due to its ease of implementation [21]. This estimator is based on the minimization of the square deviation between observations and supposed model of the signal. The difference is given by the following expression

$$
\widehat{\mathbf{v}}=\underset{\{\mathbf{v}\}}{\operatorname{argmin}}\left\|\mathbf{x}(n)-\mathbf{A}\left(\widehat{f}_{k}\right) \mathbf{v}\right\|^{2} .
$$

Once frequencies are estimated based on the proposed approaches in the above section, the corresponding solution of the previous cost function is given by

$$
\widehat{\mathbf{v}}=\left(\mathbf{A}^{H}\left(\widehat{f}_{k}\right) \mathbf{A}\left(\widehat{f}_{k}\right)\right)^{-1} \mathbf{A}^{H}\left(\widehat{f}_{k}\right) \mathbf{x}(n) .
$$

Finally, the amplitudes estimation is given by

$$
\widehat{a}_{k}=\left|\widehat{\mathbf{v}}_{k}\right|
$$

where $\widehat{\mathbf{v}}_{k}$ the $k^{t h}$ component of $\widehat{\mathbf{v}}$ and $|$.$| denotes the complex$ modulus.

\section{B. Fault Severity Criterion}

In order to detect the fault severity, we propose a criterion based on the evaluation of frequency component amplitudes previously estimated. The fault severity criterion is expressed mathematically as follows

$$
C=\frac{\sum_{k \in \theta_{1}} a_{k}^{2}}{\sum_{l \in \theta_{2}} a_{l}^{2}},
$$

where

- $\theta_{1}$ corresponds to the integers $k$ that belong to $[0, L-1]$ for which $\left|f_{k}-n f_{s}\right|>\Delta f(n \in \mathbb{N})$,

- $\theta_{2}$ corresponds to the integers $l$ that belong to $[0, L-1]$ for which $\left|f_{l}-n f_{s}\right|<\Delta f(n \in \mathbb{N})$,

- $\Delta f=10^{-2} f_{s}$ is the authorized variation of frequency values.

The fault severity criterion is inspired from the total harmonic distortion (THD) of a signal [22]. This criterion allows 


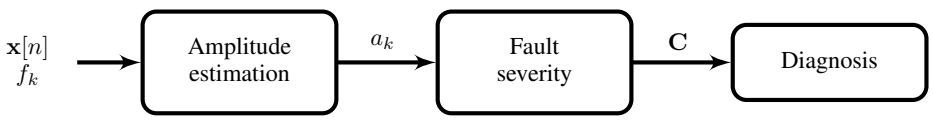

Fig. 2. Fault detection criterion computation.

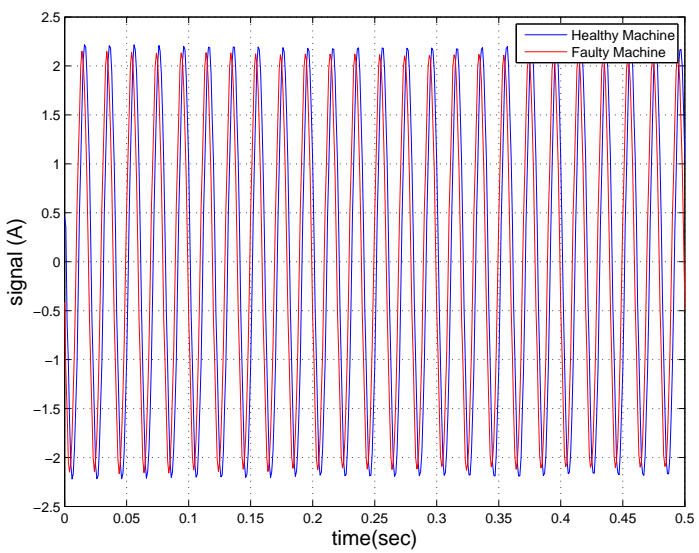

Fig. 3. The stator current for healthy and faulty induction motors.

to measure the fault severity. It can be implemented for realtime monitoring of an induction machine as described in Fig 2 .

\section{EXPERIMENTAL RESULTS}

The efficiency of the proposed approach is demonstrated on experimental stator currents issued from an induction machine with bearing faults. Several fault degrees are considered which shows the ability of the proposed criterion to track fault severity.

\section{A. Experimental Setup Description}

The above signal processing methods are tested on experimental data recorded from an induction machine with bearing fault. The machine under test is a $230 / 400 \mathrm{~V}, 0.75-\mathrm{kW}$, three phases induction motor with pole pairs number $p=1$ and $2780 \mathrm{rpm}$ rated speed. Bearing faults are obtained by simply drilling holes in the bearing. The stator currents acquisition is performed by a 24 bits acquisition card with $10 \mathrm{kHz}$ sampling frequency. These stator currents have been processed offline to reveal the presence of the fault using the proposed approaches. For all the experiments, the stator fundamental frequency was almost equal to $f_{s}=50 \mathrm{~Hz}$.

\section{B. Bearing Faults Detection}

The stator currents for healthy and faulty induction motors are given by Fig. 3 Figure 4 gives the corresponding periodogram using Hanning window. This figure shows that the periodogram does not allow to clearly distinguish frequencies. Thus, the periodogram can be used as an estimator of the spectrum, but it suffers the poor frequency resolution.

Figures 5 and 6 display high-resolution spectrum for healthy and faulty induction motors. For each representation, we can observe a difference between the periodogram and the high-resolution methods. This difference is explained by

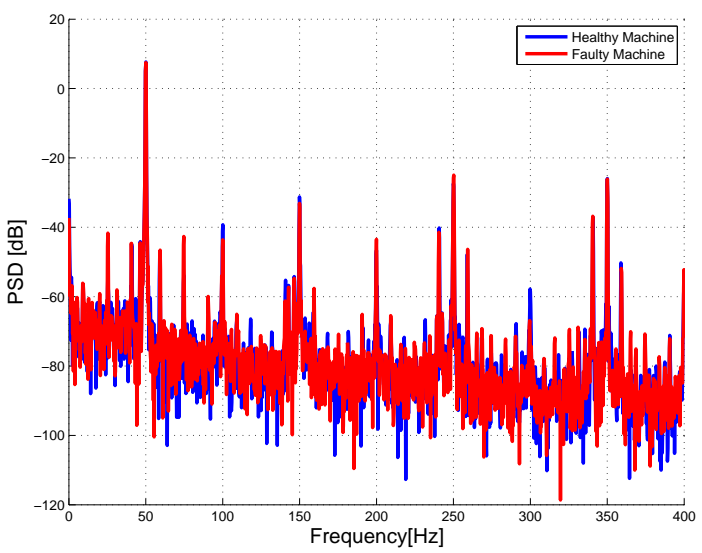

Fig. 4. Spectral analysis by Welch Periodogram using Hanning window $(\mathrm{N}=4096)$ for a healthy and faulty induction motors.

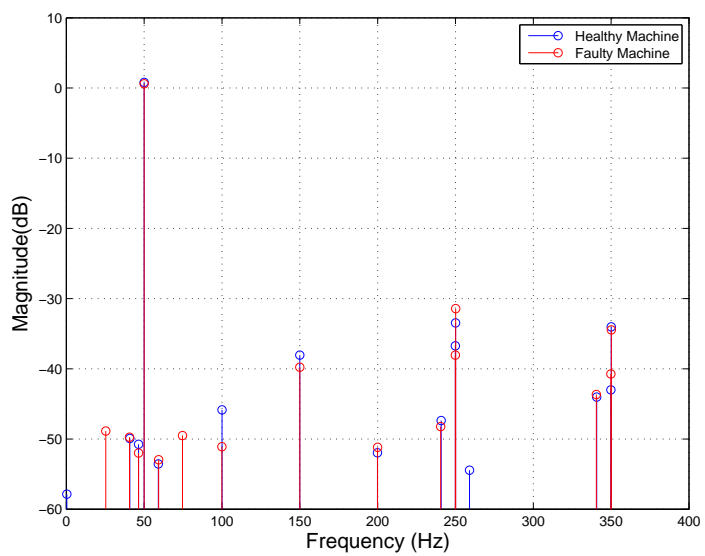

Fig. 5. The frequency estimations for a healthy and faulty induction motors are obtained with the Root-MUSIC for $\mathrm{L}=20$. The model order estimation is obtained thanks to two proposed information criteria (AIC and MDL).

the readability and the resolution capacity of high-resolution techniques compare to the periodogram. Indeed these figures show that it is possible to detect bearing fault signatures by high-resolution techniques. Moreover, faults in the induction machine are manifested by increased amplitudes associated to fault frequencies.

Several experiments have been conducted with various fault degrees. The evolution of fault detection criterion is given by Fig 7. This figure shows that the value of the fault severity criterion increases when the fault severity increases. This figure shows that it is possible to detect the fault severity in induction machine using the proposed criterion.

\section{CONCLUSION}

In this paper, we have proposed a new condition monitoring architecture for induction machines based on subspace methods for frequency estimation and the least squares estimator for amplitude estimation. These techniques offer better frequency resolution than periodogram applications for short data signals with stator current analysis. The major advantage of the proposed architecture is the ability to extract automatically the fault signature as well as giving the fault severity. The usefulness of the proposed condition monitoring architecture 


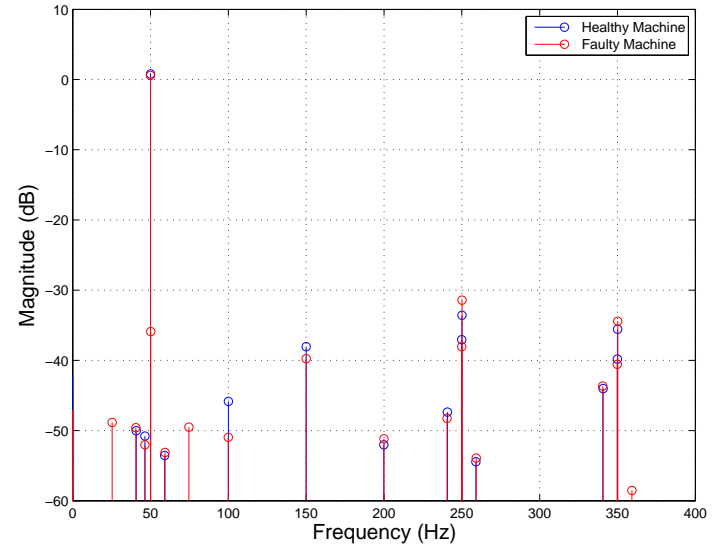

Fig. 6. The frequency estimations for a healthy and faulty induction motors are obtained with the ESPRIT for $\mathrm{L}=20$. The model order estimation is obtained thanks to two proposed information criteria (AIC and MDL).

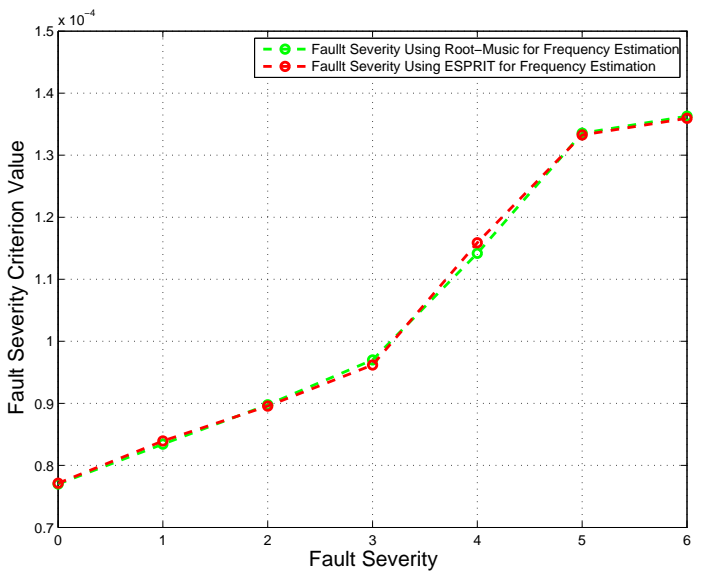

Fig. 7. Fault severity criterion value for different fault degrees in induction motors.

have been demonstrated for bearing faults detection on an actual induction machine.

The proposed approaches can be easily implemented at a reasonable computational cost in real-world industry applications such as variable speed drives and renewable energy applications.

\section{REFERENCES}

[1] P. Zhang, Y. Du, T. G. Habetler, and B. Lu, "A survey of condition monitoring and protection methods for medium-voltage induction motors," IEEE Transactions on Industry Applications, vol. 47, no. 1, pp. 34-46, January/ February 2011.

[2] M. Blodt, J. Regnier, and J. Faucher, "Distinguishing load torque oscillations and eccentricity faults in induction motors using stator current Wigner distributions," IEEE Transactions on Industry Applications, vol. 45, no. 6, pp. 1991-2000", November/ December 2009.

[3] E. Elbouchikhi, V. Choqueuse, M. E. H. Benbouzid, and J.-F. Charpentier, "Induction machine fault detection enhancement using a stator current high resolution spectrum," in IECON 2012-38th Annual Conference on IEEE Industrial Electronics Society, (Montreal, Canada), pp. 3913-3918, IEEE, October 2012.

[4] H. A. Toliyat, S. Nandi, S. Choi, and H. Meshgin-Kelk, Electric Machines: Modeling, Condition Monitoring, and Fault Diagnosis. CRC Press, October 2012.
[5] M. E. H. Benbouzid and G. B. Kliman, "What stator current processingbased technique to use for induction motor rotor faults diagnosis?," IEEE Transactions on Energy Conversion, vol. 18, no. 2, pp. 238-244, June 2003

[6] A. Garcia-Perez, R. J. Romero-Troncoso, E. Cabal-Yepez, R. OsornioRios, J. de Jesus Rangel-Magdaleno, H. Miranda, et al., "Startup current analysis of incipient broken rotor bar in induction motors using highresolution spectral analysis," in 2011 IEEE International Symposium on Diagnostics for Electric Machines, Power Electronics \& Drives (SDEMPED), (Bologna, Italy), pp. 657-663, September 2011.

[7] M. Blodt, P. Granjon, B. Raison, and G. Rostaing, "Models for bearing damage detection in induction motors using stator current monitoring," IEEE Transactions on Industrial Electronics, vol. 55, no. 4, pp. 18131822, April 2008.

[8] V. Choqueuse, M. E. H. Benbouzid, Y. Amirat, and S. Turri, "Diagnosis of three-phase electrical machines using multidimensional demodulation techniques," IEEE Transactions on Industrial Electronics, vol. 59, no. 4, pp. 2014-2023, April 2012.

[9] E. Elbouchikhi, V. Choqueuse, and M. E. H. Benbouzid, "Current frequency spectral subtraction and its contribution to induction machines bearings condition monitoring," IEEE Transactions on Energy Conversion, vol. 28, no. 1, pp. 135-144, March 2013.

[10] S. Nandi, H. A. Toliyat, and X. Li, "Condition monitoring and fault diagnosis of electrical motors-a review," IEEE Transactions on Energy Conversion, vol. 20, no. 4, pp. 719-729, December 2005.

[11] Y.-H. Kim, Y.-W. Youn, D.-H. Hwang, J.-H. Sun, and D.-S. Kang, "High-resolution parameter estimation method to identify broken rotor bar faults in induction motors," IEEE Transactions on Industrial Electronics, vol. 60, no. 9, pp. 4103-4117, September 2013.

[12] M. E. H. Benbouzid, M. Vieira, and C. Theys, "Induction motors' faults detection and localization using stator current advanced signal processing techniques," IEEE Transactions on Power Electronics, vol. 14, no. 1, pp. 14-22, January 1999.

[13] B. Xu, L. Sun, L. Xu, and G. Xu, "Improvement of the Hilbert method via ESPRIT for detecting rotor fault in induction motors at low slip," IEEE Transactions on Energy Conversion, vol. 28, no. 1, pp. 225-233, March 2013

[14] R. Schoen, T. Habetler, F. Kamran, and R. Bartheld, "Motor bearing damage detection using stator current monitoring," IEEE Transactions on Industry Applications, vol. 31, no. 6, pp. 1274-1279, November/ December 1995.

[15] M. Wax and T. Kailath, "Detection of signals by information theoretic criteria," IEEE Transactions on Acoustics, Speech and Signal Processing, vol. 33, no. 2, pp. 387-392, April 1985.

[16] E. Elbouchikhi, V. Choqueuse, and M. E. H. Benbouzid, "Nonstationary spectral estimation for wind turbine induction generator faults detection," in IECON 2013-39th Annual Conference on IEEE Industrial Electronics Society, (Vianna, Austria), pp. 7376-7381, IEEE, November 2013.

[17] R. O. Schmidt, "A signal subspace approach to multiple emitter location spectral estimation," Ph. D. Thesis, Stanford University, 1981

[18] P. Stoica and R. L. Moses, Introduction to Spectral Analysis, vol. 1. Prentice hall Upper Saddle River, NJ, February 1997.

[19] R. Roy and T. Kailath, "ESPRIT-estimation of signal parameters via rotational invariance techniques," IEEE Transactions on Acoustics, Speech and Signal Processing, vol. 37, no. 7, pp. 984-995, July 1989.

[20] D. G. Manolakis, V. K. Ingle, and S. M. Kogon, Statistical and Adaptive Signal Processing: Spectral Estimation, Signal Modeling, Adaptive Filtering, and Array Processing, vol. 46. Artech House Norwood, April 2005.

[21] P. Stoica, H. Li, and J. Li, "Amplitude estimation of sinusoidal signals: survey, new results, and an application," IEEE Transactions on Signal Processing, vol. 48, no. 2, pp. 338-352, February 2000.

[22] E. Fuchs and M. A. Masoum, Power Quality in Power Systems and Electrical Machines. Academic Press, March 2011. 